\title{
O USO E CONHECIMENTOS BÁSICOS SOBRE PLANTAS MEDICINAIS NO ENSINO FUNDAMENTAL PARA A PROMOÇÃO DA SAÚDE E QUALIDADE DE VIDA
}

Thiago da Silva Batista ${ }^{1}$; Renata Thaysa dos Santos Cunha ${ }^{2}$; Jardielle de Lemos Silva²; Maria Carolina Sotero ${ }^{2}$.

1Lic. Em Ciências Biológicas, Centro Acadêmico de Vitória-UFPE, thiago__batista@hotmail.com

${ }^{2}$ Lic. Em Ciências Biológicas, Centro Acadêmico de Vitória-UFPE, renatajbthaysa@ gmail.com

${ }^{2}$ Lic. Em Ciências Biológicas, Centro Acadêmico de Vitória-UFPE, jardy1@ hotmail.com

2Mestre em Desenvolvimento e Meio Ambiente, PRODEMA/UFPE, carol.sotero@ yahoo.com.br

\section{Introdução}

Desde os tempos mais antigos o homem busca na natureza recursos para melhorar sua própria condição de vida. Quando, ao passar dos anos, se descobria que as plantas tinha um efeito sobre o organismo e atribuíam este fato a rituais religiosos (LORENZI e MATOS,2002). As plantas medicinais são usadas desde a antiguidade pelo homem no tratamento de doenças, onde previne ou cura as doenças chegando muitas vezes a torna-se hábitos do dia a dia dos mais antigos. (MORAES; SANTANA, 2001).

A definição da Resolução da Diretoria Colegiado n 26/2014 da Agência de Vigilância Sanitária do Ministério da Saúde do Brasil (BRASIL, 2014), São considerados medicamentos fitoterápicos os obtidos com emprego exclusivo de matérias-primas ativas vegetais cuja segurança e eficácia sejam baseadas em evidências clínicas e que sejam caracterizados pela constância de sua qualidade. Desse modo, essas plantas medicinais que fazem parte do cotidiano de diversas regiões, no Brasil, pelo interesse dos serviços de fototerapia no SUS, através das ações praticadas pelo Ministério da saúde, tem promovido melhor qualidade de vidas as pessoas.

É valido que exista uma interação da escola com os temas que podem ser trabalhados nas aulas, os quais estimulam um maior interesse aos estudantes. As plantas medicinais é um conteúdo importante para ser utilizado antes de introduzir o assunto do Reino Plantae, e a partir, de uma breve apresentação do mesmo desenvolver atividades que busque os conhecimentos prévios dos discentes, e estimule a vivência de práticas que colaborem com a promoção da saúde e qualidade vida.. 
Towata e colaboradores (2010), explicam que os professores precisam tornar a aula mais próxima da realidade do aluno, ou seja, trazendo aulas práticas correlacionadas com os conteúdos visto no cotidiano dos discentes. Dessa forma a aprendizagem do aluno com práticas tornam mais agradáveis e atrativas, sempre chamando a atenção dos alunos, o que faz com eles aprendam com a vivência.

Nesse sentido, o presente estudo objetiva avaliar as concepções prévias dos alunos sobre o uso das plantas medicinais, assumindo como premissa criar competências e habilidades comprometidas com a promoção da saúde e a qualidade de vida, em uma perspectiva individual e coletiva.

\section{Fundamentação Teórica}

O campo das Ciências Naturais atualmente é marcado por alguns avanços em relação a processos metodológicos. Entretanto a área da botânica não é impactada com tais processos, pois quando nos referimos a deixar raízes de ensino tradicionais partindo para metodologias onde o aluno deixa de ser passivo e o professor único detentor do conhecimento, os autores Kinoshita et al. (2006) definem o ensino de botânica na educação básica como muito teórico e desestimulante para os alunos, sendo também o menos valorizado dentro do campo das ciências.

Como descrito anteriormente, segundo Wandersee et al. (2001), o pilar que sustenta o grande déficit no ensino de botânica é a falta de estimulo para se estudar os vegetais, partindo da incapacidade de relacionar importâncias entre esses organismos e ambiente, originando um termo determinado pelo mesmo como "Cegueira botânica".

Mesmo as dificuldades no processo de ensino-aprendizagem dentro de botânica, partindo da não habilidade de compreender a importância desses organismos para vida dos seres humanos, o conhecimento dos vegetais ocorre desde os primeiros estudos do homem como diz Chassot (2003):

[...] o estudo das plantas fez parte dos primeiros conhecimentos do homem, pois este necessitava selecionar raízes, caules, folhas, frutos e sementes, destinados à alimentação, vestuários e construções.”, logo é notável a interação do homem com as plantas, mesmo que essa passe despercebida em muitos momentos. (CHASSOT, 2000, p. 15)

Guillich (2007) vem completar o pensamento abordado anteriormente quando fala da relação homem-planta desde os primórdios da historia humana.

[...] Registros de Epígenes sobre observações astronômicas realizadas por frígios, arcádios e egípcios, em rochas de cavernas, pintadas com extratos vegetais, demonstram a antiguidade das relações homem-planta. (GÜILLICH, 2007, p. 26). 
Essas relações descritas anteriormente, permeiam a esfera das plantas medicinais quando as mesmas são usadas pelo homem no tratamento de doenças, onde previne ou cura as doenças chegando muitas vezes a torna-se hábitos do dia a dia dos mais antigos. (MORAES; SANTANA, 2001).

\section{Metodologia}

A linha metodológica seguiu abordagens qualitativas descritas por Minayo (1993), onde o mesmo distingue o homem de objetos, estabelecendo assim práticas humanas, ou seja, fazendo necessária uma metodologia que considere as diferenças, excetuando-se a abordagem quantitativa.

O presente estudo fundamentou-se na investigação de conhecimentos prévios e importâncias das plantas medicinais, seguida aplicações de estratégias metodológicas que tornassem os alunos sujeitos ativos e participantes do processo.

A coleta de dados foi realizada na Escola Municipal Professora Aglaires Silva da Cruz Moura, localizada no município de Vitória de Santo Antão. Inicialmente foi aplicado um questionário, com intuito de avaliar os conhecimentos prévios dos alunos sobre o uso e importância das plantas medicinais (PMs). Posteriormente, uma aula expositiva dialogada foi construída a fim de repassar conceitos, construir conhecimentos e reformular ideias pré-existentes sobre as PMs. Ao final da mesma, os alunos foram estimulados a confeccionar cartazes educativos mostrando a utilização e importâncias de algumas PMs. Em seguida, com o termino do bloco prático, um novo questionário foi proposto avaliando os conhecimentos adquiridos pelos alunos durante a aula.

\section{Resultados e Discussões}

Em relação aos conhecimentos prévios dos alunos sobre a temática trabalhada, os mesmo forma questionados sobre alguns blocos como; conhecimentos sobre plantas medicinais, utilização das plantas medicinais e atuação das plantas medicinais como medicamentos.

Os dados obtidos correspondem a um universo de 14 alunos do $7^{\circ}$ ano do Ensino Fundamental, onde 78,5\% apresentam algum conhecimento sobre as plantas medicinais, onde destes $73 \%$ fazem ou já fizeram uso desses vegetais, contudo os processos associados envolvem apenas a utilização de chás, excetuando-se infusões e ingestões diretas. Enquanto que apenas 3 alunos $(21,5 \%)$ afirmam não saber o que são as plantas medicinais e suas utilidades. Os percentuais obtidos apresentam uma positividade quando comparados aos estudos de Rangel (2009), onde a mesma afirma que as plantas medicinais são salientadas devido as suas potencialidades terapêuticas aplicadas ao longo das gerações, sendo assim, o conhecimento sobre as mesmas de extrema importância. 
Para Marinho et al. (2011), os estudos relacionados com a medicina popular têm merecido cada vez mais atenção, em virtude da gama de informações e esclarecimento à ciência. Nesse sentido, as plantas medicinais ganham destaque sendo elas comumente utilizadas como medicamentos. Para essa linha, foi encontrado um percentual de $71 \%$ de alunos que compreendiam a utilização das plantas medicinais como medicamentos, enquanto os demais (4 alunos) afirmam a necessidade de consultar um medico antes de ingerir qualquer medicação.

É notório o conhecimento prévio dos alunos sobre as plantas medicinais e suas utilidades, contudo se faz necessário a utilização de metodologias que busquem essa temática, onde o professor atua como mediador e constrói com os alunos alguns conhecimentos pertinentes, visando a promoção da saúde e qualidade de vida, quando o mesmo instiga os conteúdos atitudinais dos educandos.

Após a aula expositiva dialogada os alunos confeccionam cartazes (Figura 1) onde os alunos elucidam a importância em conhecer algumas plantas medicinais e suas utilidades. Foi perceptível também uma melhor compreensão sobre o que são as plantas medicinais, onde todos os participantes (14 alunos) agregaram o conhecimento que permeiam os estudos de Foligo (2006), onde a mesma considera as plantas medicinais como aquelas plantas administradas sob qualquer forma e por alguma via ao homem, exercendo algum tipo de ação farmacológica.

Figura 1: Montagem dos cartazes sobre plantas medicinais e suas utilidades.

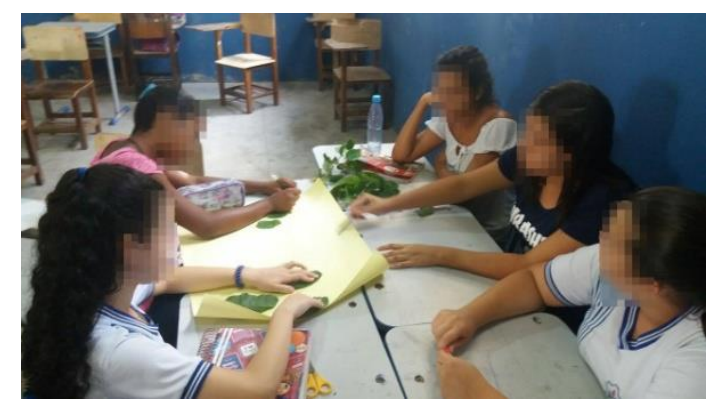

Fonte: Autor

\section{Conclusão}

O trabalho descrito possibilitou avaliar um panorama pré e um pós intervenção, onde foi notório o conhecimento prévio dos alunos sobre plantas medicinais, contudo apresentando algumas falhas. Entretanto, após a aula um conhecimento sobre plantas medicinais e suas utilidades bem fundamentado foi alcançado, promovendo aos alunos uma prática que leve a promoção da saúde e qualidade de vida. Foi notório também, a importância de se trabalhar conhecimento popular na 
esfera das plantas medicinais na educação básica, fornecendo assim subsídios aos alunos para efetuar práticas coerentes no dia a dia.

\section{Referências}

BUCARESKY, I. Programas de boas práticas regulatórias. Agência Nacional de Vigilância Sanitária - Anvisa. Brasília, 2015.

CHASSOT, A. Alfabetização científica: questões e desafios para a educação. Ijuí: Ed. Unijuí, 2003.

FOGLIO, M.A et al. Plantas Medicinais como Fonte de Recursos Terapêuticos: Um Modelo Multidisciplinar. 2006. In: Construindo a História dos Produtos Naturais. MultiCiência. CPQBA/UNICAMP. Disponível em: http://www.multiciencia.unicamp.br/artigos_07/a_04_7.pdf. Acesso em:14 de out de 2017.

GÜLLICH, R. I. C. Além do pensamento botânico e aquém do conhecimento biológico: A Botânica e seus aspectos históricos. Resvista Setrem (Educação), V. 3, n. 3, p. 24-43, ago. 2003

KINOSHITA, L. S.; TORRES, R. B.; TAMASHIRO, J. Y. ; MARTINS, E. R.. A Botânica no Ensino Básico: relatos de uma experiência transformadora. São Carlos: Rima, 2006.

CHASSOT, A. Alfabetização científica: questões e desafios para a educação. Ijuí: Ed. Unijuí, 2003.

LORENZI, H. MATOS, F.J.A. Plantas medicinais do Brasil: nativas e exóticas. Nova Odesa: Plantarum, 2002, 544 p.

MARINHO, M.G.V.; SILVA, C.C.; ANDRADE, L.H.C. Levantamento etnobotânico de plantas medicinais em área de caatinga no município de São José de Espinharas, Paraíba, Brasil. Revista Brasileira de Plantas Medicinais, v.13, n.2, p.170-182, 2011

MORAES, M.E.A.; SANTANA, G.S.M. Aroeirado-sertão: um canditado promissor para o tratamento de úlceras gástricas. Funcap, v. 3, p. 5-6, 2001.

RANGEL, M, Bragança FCR. Representações de gestantes sobre o uso de plantas medicinais. Rev Bras Pl Med. 2009 Jan-Mar; 11(1):100-9.

TOWATA, N.; Ursi, S.; Santos, D. Y. A. C. Análise da percepção dos licenciandos sobre o 'ensino de botânica na educação básica'. Revista da SBenBio. 03: 1603-1612. 2010.

WANDERSEE, J. H.; SCHUSSLER, E. E. Towards a theory of plant blindness. Plant Science Bulletin. USA, v. 47, n. 1, p. 2-9, dez. 2001. 